\title{
Microphysiological systems and low-cost microfluidic platform with analytics
}

\author{
Alec ST Smith', Christopher J Long', Bonnie J Berry', Christopher McAleer', Maria Stancescu', Peter Molnar², \\ Paula G Miller², Mandy B Esch², Jean-Matthieu Prot ${ }^{2}$, James J Hickman*1 and Michael L Shuler ${ }^{2}$
}

\begin{abstract}
A multiorgan, functional, human in vitro assay system or'Body-on-a-Chip' would be of tremendous benefit to the drug discovery and toxicology industries, as well as providing a more biologically accurate model for the study of disease as well as applied and basic biological research. Here, we describe the advances our team has made towards this goal, as well as the most pertinent issues facing further development of these systems. Description is given of individual organ models with appropriate cellular functionality, and our efforts to produce human iterations of each using primary and stem cell sources for eventual incorporation into this system. Advancement of the 'Body-on-a-Chip' field is predicated on the availability of abundant sources of human cells, capable of full differentiation and maturation to adult phenotypes, for which researchers are largely dependent on stem cells. Although this level of maturation is not yet achievable in all cell types, the work of our group highlights the high level of functionality that can be achieved using current technology, for a wide variety of cell types. As availability of functional human cell types for in vitro culture increases, the potential to produce a multiorgan in vitro system capable of accurately reproducing acute and chronic human responses to chemical and pathological challenge in real time will also increase.
\end{abstract}

\section{Introduction}

Model physiological systems that integrate different human cell types, while maintaining normal physiological responses and month-long cell viability in defined, serumfree media, are needed to facilitate the replacement of

*Correspondence: jhickman@mail.ucf.edu

'NanoScience Technology Center, University of Central Florida, Orlando, FL 32826, USA

Full list of author information is available at the end of the article animals in preclinical drug screens with in vitro platforms. Our team's philosophy is to keep these systems as simple as possible to hold down cost and only add complexity to enable increased functionality, if needed for better evaluation capabilities. Design of our systems is guided by a computer model of the body (a physiologically based pharmacokinetic (PBPK) pharmacodynamic model), referred to as a micro-cell culture analog $(\mu \mathrm{CCA})$ or a 'Body-on-a-Chip'. In an article entitled 'Tissue Models: A Living System on a Chip' [1], Shuler's group is credited with conceiving of this approach, and with demonstrating its broad feasibility. Our in vitro system, unlike other in vitro methods, provides realistic dose dynamics and allows for metabolite exchange between compartments. Furthermore, the natural length scale of the model (10 to $100 \mu \mathrm{m})$ is consistent with physiological length scales.

Hickman's group has developed a defined base media system that enables culture of a wide range of cell types for many months, and removes a major variable (serum) from the system. Hickman's group published the first serum-free, defined culture system for neurons in 1995 [2] and has since then advanced this work from the use of rodent cells to human cells. In most cases, the cultured cells have been shown to maintain functionality for at least 2 to 3 months in this system. This common, defined media system utilization has been expanded to include human neurons $[3,4]$, glia $[5,6]$, muscle [3] and cardiomyocytes [7] from adult, fetal and embryonic stem cell sources. Hickman's group has progressed in the creation of a functional neuromuscular junction model for rat-rat [8] to rat-human [4] to human-human [3] using the same basic serum-free culture system.

Owing to space constraints, a complete overview of the design and validation of all current 'Body-on-a-Chip' technologies is beyond the scope of this article. For a more complete assessment of the field, refer to the reviews in $[9,10]$ and references cited therein. This paper will instead highlight the advances our group has made in developing a multiorgan 'Body-on-a-Chip' platform, as well as our achievements in developing functional assays of a variety of tissues for eventual integration into this model. 


\section{Design and validation of a multiorgan in vitro system}

The fabrication of a microfluidic device that used living cell tissue constructs, interconnected as they are in the body, was conceived by Shuler, Baxter and others (US Patent \#7,288,405 2007). The concept for a 'Body-on-aChip' microphysiological system comes from the desire to emulate a PBPK pharmacodynamic mathematical model using a physical model. By combining PBPK pharmacodynamic models with the experimental device, the quality of predictions and depth of understanding can be increased [11,12]. Shuler's group has demonstrated such a device and its use in emulating key aspects of the human response to combination treatment of colon cancer, using tegafur and uracil [12].

This effort is currently being expanded by exploring designs of devices with up to 13 tissue compartments. Figure 1 shows the design of a 10-compartment system currently in development. Measurements can be made using microscopy, integrated microelectrode arrays, biomicroelectromechanical system (BioMEMS) devices and using conditioned medium samples sent to microanalytical systems. Initial tests demonstrate that this system can maintain high cell viability ( 85 to $95 \%$ ) in all compartments using HepG2-C3A cells, over a 48-hour period, without medium replacement. The fluid flow to each compartment is consistent with design values, and the overall blood surrogate recirculation time (approximately 6 minutes) is consistent with the expected physiological value.

\section{Cardiac model}

The Hickman group has developed an in vitro method for pharmacological cardiac side-effect testing, which uses surface-modified commercially available multi-electrode arrays (MEAs). The surface of the multi-electrode array is patterned with a cytophobic polyethylene-glycol selfassembled monolayer, and the cytophilic biopolymer fibronectin [7]. Rat cardiac myocytes plated onto patterned multi-electrode arrays are stable in culture for at least 60 days, and have been used to test functional responses to two drugs: 1-heptanol, a gap junction blocker; and sparfloxacin, a fluoroquinone antibiotic. Integration of these systems with BioMEMS cantilever devices also allows for direct force measurement to be made.

\section{Central/peripheral nervous system and skeletal muscle models}

The culture parameters for the long-term maintenance and maturation of both embryonic and adult rat hippocampal neurons in serum-free conditions have been established by the Hickman group [13]. Such cells are amenable to interrogation with patch clamp electrodes
[13] and multi-electrode arrays [14], and display mature morphology as well as electrical function.

We have published extensively on the establishment of motoneuron [15,16] and muscle [17] cultures, utilizing cells from both human stem cell $[3,4,15]$ and rodent $[16,18]$ sources. Furthermore, our group has detailed the development of human stem-cell-derived co-cultures for analysis of neuromuscular junction formation in vitro [3]. Human motoneuron-muscle co-cultures, cultured using our protocols, have been shown to survive for $30+$ days in vitro and to form synaptic connections responsive to stimulation with excitatory neurotransmitters (for example, glutamate) and to be inhibited through treatment with acetylcholine receptor antagonists (for example, Dtubocurarine) [3]. Muscle-only systems have been integrated with BioMEMS cantilever chips to allow direct force readouts of muscle function $[17,19,20]$.

The Hickman laboratory has also demonstrated the capacity to maintain co-cultures of rat intrafusal muscle fibers with sensory neurons [21]. Recently, we published the first in vitro culture model capable of differentiating and maintaining human, stem-cell-derived sensory neurons displaying full electrical functionality [22]. We are currently working on developing a model capable of replicating all aspects of the reflex arc with human cells in vitro [23].

\section{Lung model}

The Hickman and Shuler groups have developed a microfluidic device that reproduces the microenvironment of the lung alveoli, to produce controlled gas concentrations in both the gas and liquid sides of the alveolus-capillary interface, and to measure changes in functional gas transfer through the epithelial-endothelial bilayer [24]. The alveolar microfluidic device contains a number of chambers for microenvironment maintenance and monitoring. The primary chamber was designed to contain the cellular alveolus-capillary interface construct. An upstream conditioning chamber was incorporated to control the dissolved gas concentrations in the incoming liquid, acting as a blood analog, and downstream chambers were included to house dissolved gas sensors for monitoring output concentrations. This silicon-based device allows the control and maintenance of gas concentrations in both gas and liquid chambers. Changes to the health of the alveoli can be monitored under various conditions including restricted lung capacity, altered blood compositions, and disease states involving the alveolar-capillary interface.

\section{Gastrointestinal tract/liver model}

Absorbed drugs that have crossed the gastrointestinal tract mucosa and epithelium are transported directly to the liver via the portal vein. 'Body-on-a-Chip' constructs, 


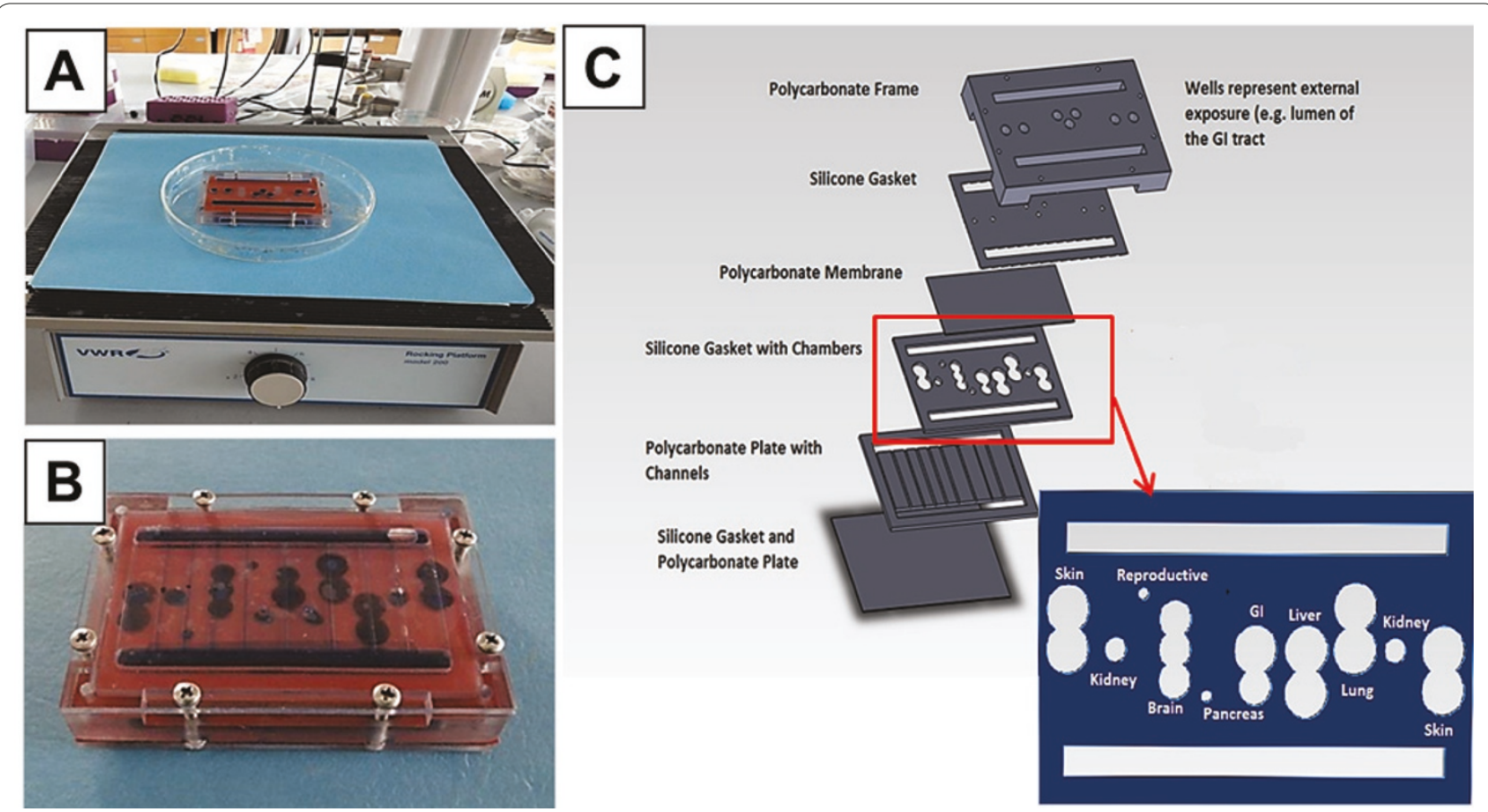

Figure 1. Overview of a 10-chamber in vitro model. Overview of our 10-chamber in vitro model based on a simplified three-chamber system using gravity-driven flow [12]. (A) Prototype unit on a rocker platform. (B) Close-up inverted view of the prototype unit after a dye distribution study. (C) Exploded schematic showing the compartmentalization design for a 10-chamber system within this single unit. Barrier tissues (for example, gastrointestinal (Gl) tract, skin, and so forth) are made by plating cells and allowing them to grow into a layer on a pretreated polycarbonate membrane $(0.4 \mu \mathrm{m}$ pore size) that was sandwiched between a chamber gasket and another gasket or a polycarbonate channel plate creating chambers for the cells. The design provides an apical and a basolateral side for each chamber, allowing passage of chemicals across the barrier. Nonbarrier tissues are three-dimensional constructs made by resuspending cells in hydrogels or plating them on a polymeric scaffold. The three-dimensional tissue constructs are placed directly onto a polycarbonate membrane that is again sandwiched between a chamber gasket and another gasket or polycarbonate channel plate creating the chambers for the cells.

that contain both the gastrointestinal tract and the liver, can therefore simulate the uptake and first-pass metabolism of drugs. The detection of metabolites of acetaminophen within such a system has recently confirmed that this is possible with a two-organ in vitro model by Shuler and colleagues [25].

Shuler's group and others have expanded simple Caco-2 cell culture models to two-cell-type and threecell-type cultures that consist of Caco-2 cells, mucusproducing HT-29 cells, and M-cells [26,27]. Using this system Shuler and colleagues have recently simulated the oral uptake of 50 and $200 \mathrm{~nm}$ polystyrene particles, and have found that $\mathrm{M}$-cells are needed to simulate the uptake of the larger particles [27]. The group has also developed microfluidic models that contained this threecell-type gastrointestinal tract tissue and simulated the uptake of acetaminophen and its subsequent actions in the liver [25]. PBPK simulations of these devices indicated that after 24 hours the acetaminophen dose in the device was $\sim 90 \%$ of that expected in humans after 24 hours. They have begun to culture Caco-2 cells on three-dimensional surfaces that allow the cells to form macro-villi, thereby enabling drug transport studies across a three-dimensional tissue interface [28,29].

Sung and Shuler have developed a micro-device that uses Matrigel and confers a three-dimensional environment which facilitates the expression of CYP450 enzymes by cultured hepatocytes [30]. The current work concentrates on the integration of primary hepatocytes with non-parenchymal cells, cultivated in a three-dimensional scaffold [31], to better mimic the physiological situation. Initial experiments using non-parenchymal cells and a HepG2/C3A liver model, cultivated in our gravity-driven flow device, have shown sustained biological activity for 28 days in vitro, including inducible CYP450 activity (CYP1A1 and CYP3A4) and albumin synthesis.

\section{Barrier tissues model}

Shuler's approach to modeling the blood-brain barrier is to utilize microfabricated membranes, which are manufactured as integral parts of microfluidic chambers $[28,32]$, to culture brain endothelial cells and astrocytes within microfluidic chambers. These will enable the testing of hypotheses related to the need for physical 
contact between endothelial cells and astrocytes. Recent work by Lippmann and colleagues [33] and by Shayan and colleagues [34] has shown that brain endothelial cells respond to the presence of astrocytes in culture, acquiring substantial barrier properties, as indicated by high transendothelial electrical resistance measurements.

Shuler's work in developing an in vitro model of the capillary network has focused on characterizing endothelial cell (human umbilical vein endothelial cell) growth in small microfluidic vessels $(50 \mu \mathrm{m} \times 50 \mu \mathrm{m})$. In vessels of this size, the sidewalls become significant surfaces. Characterization with confocal microscopy has shown that human umbilical vein endothelial cells grown in small microfluidic channels exhibit barrier function (as indicated by immunostained vascular endothelial cadherin) throughout the vessels and even on the sidewalls when the cells are cultured under sufficient shear stress [35].

\section{Fat model}

Since 'Body-on-a-Chip' models must include the complete set of organs either implicitly or explicitly, the fat compartment is often included implicitly. However, modeling the fat compartment explicitly may have advantages. In experiments with environmental toxins (naphthalene) Shuler has found that the presence of a fat compartment, represented by differentiated 3T3-L1 adipocytes, modulates the response of the system (in particular, lung cells) to the toxin. Adipocytes presumably ameliorate damage to co-cultured cells through absorption of toxins and damaging compounds, such as hydrogen peroxide, and prevention of glutathione depletion [36].

\section{Conclusions}

Our groups have focused on developing increasingly authentic functional tissue constructs to incorporate into a multi-tissue platform based on a PBPK model. While there are significant challenges in constructing an integrated 10-organ, all-human system, the advances so far made by our team lead us to believe we have a good basis to construct a functional human model. Issues such as availability, cost, and ability to display adult cell physiology and phenotype will soon be solved, to allow greater incorporation of stem cells into these modules and ultimately more authentic tissue constructs and improved modules in this microphysiological system.

\footnotetext{
Abbreviations

BioMEMS, bio-microelectromechanical system; PBPK, physiologically based pharmacokinetic.
}

\section{Competing interests}

HuRel has licensed Cornell patents (for example, US Patent 5,728,580 (1998) and US Patent 7,288,405 (2007)) that underlie the 'Body-on-a-Chip' concept. MLS is on the scientific advisory board for HuRel.

\section{Acknowledgements}

This research was funded by National Institutes of Health grant numbers 1UH2TR000516-01, R01NS050452 and R01EB005459. The publication costs for this article were funded by National Institutes of Health grant number UH2TR000516.

\section{Declarations}

Publication of this supplement has not been supported by sponsorship. Articles have undergone the journal's standard review process. The Editors declare that they have no competing interests.

This article has been published as part of Stem Cell Research \& Therapy Volume 4 Supplement 1, 2013: Stem cells on bioengineered microphysiological platforms for disease modeling and drug testing. The full contents of the supplement are available online at http://www.stemcellres.com/supplements/4/S1.

\section{Author details}

'NanoScience Technology Center, University of Central Florida, Orlando, FL 32826, USA. ${ }^{2}$ Cornell University, Department of Biomedical Engineering, 115 Weill Hall, Ithaca, NY 14853, USA.

Published: 20 December 2013

\section{References}

1. Baker M: Tissue models: a living system on a chip. Nature 2011, 471:661-665.

2. Schaffner AE, Barker JL, Stenger DA, Hickman JJ: Investigation of the factors necessary for growth of hippocampal neurons in a defined system. J Neurosci Methods 1995, 62:111-119.

3. Guo X, Gonzalez M, Stancescu M, Vandenburgh HH, Hickman JJ: Neuromuscular junction formation between human stem cell-derived motoneurons and human skeletal muscle in a defined system. Biomaterials 2011, 32:9602-9611.

4. Guo X, Das M, Rumsey J, Gonzalez M, Stancescu M, Hickman J: Neuromuscular junction formation between human stem-cell-derived motoneurons and rat skeletal muscle in a defined system. Tissue Eng Part C Methods 2010, 16:1347-1355.

5. Davis H, Guo X, Lambert S, Stancescu M, Hickman JJ: Small molecule induction of human umbilical stem cells into MBP-positive oligodendrocytes in a defined three-dimensional environment. ACS Chem Neurosci 2012, 3:31-39.

6. Davis H, Gonzalez M, Bhargava N, Stancescu M, Hickman JJ, Lambert S: Rat cortical oligodendrocyte-embryonic motoneuron co-culture: an axonoligodendrocyte interaction model. J Biomater Tissue Eng 2012, 2:206-214

7. Natarajan A, Stancescu M, Dhir V, Armstrong C, Sommerhage F, Hickman JJ Molnar P: Patterned cardiomyocytes on microelectrode arrays as a functional, high information content drug screening platform. Biomaterials 2011, 32:4267-4274.

8. Das M, Rumsey JW, Bhargava N, Stancescu M, Hickman JJ: A defined longterm in vitro tissue engineered model of neuromuscular junctions. Biomaterials 2010, 31:4880-4888

9. Sung JH, Esch MB, Prot JM, Long CJ, Smith A, Hickman JJ, Shuler ML: Microfabricated mammalian organ systems and their integration into models of whole animals and humans. Lab Chip 2013, 13:1201-1212.

10. Huh D, Torisawa YS, Hamilton GA, Kim HJ, Ingber DE: Microengineered physiological biomimicry: organs-on-chips. Lab Chip 2012, 12:2156-2164

11. Sung JH, Dhiman A, Shuler ML: A combined pharmacokineticpharmacodynamic (PK-PD) model for tumor growth in the rat with UFT administration. J Pharm Sci 2009, 98:1885-1904.

12. Sung JH, Kam C, Shuler ML: A microfluidic device for a pharmacokineticpharmacodynamic (PK-PD) model on a chip. Lab Chip 2010, 10:446-455.

13. Edwards D, Das M, Molnar P, Hickman Jj: Addition of glutamate to serumfree culture promotes recovery of electrical activity in adult hippocampal neurons in vitro. J Neurosci Methods 2010, 190:155-163.

14. Varghese K, Molnar P, Das M, Bhargava N, Lambert S, Kindy MS, Hickman JJ: A new target for amyloid beta toxicity validated by standard and highthroughput electrophysiology. PLOS ONE 2010, 5:e8643.

15. Guo X, Johe K, Molnar P, Davis H, Hickman J: Characterization of a human fetal spinal cord stem cell line, NSI-566RSC, and its induction to functional motoneurons. J Tissue Eng Regen Med 2010, 4:181-193.

16. Das M, Bhargava N, Bhalkikar A, Kang JF, Hickman Jj: Temporal 
neurotransmitter conditioning restores the functional activity of adult spinal cord neurons in long-term culture. Exp Neurol 2008, 209:171-180.

17. Das M, Wilson K, Molnar P, Hickman JJ: Differentiation of skeletal muscle and integration of myotubes with silicon microstructures using serumfree medium and a synthetic silane substrate. Nat Protoc 2007, 2:1795-1801.

18. Das M, Rumsey JW, Bhargava N, Stancescu M, Hickman JJ: Skeletal muscle tissue engineering: a maturation model promoting long-term survival of myotubes, structural development of the excitation-contraction coupling apparatus and neonatal myosin heavy chain expression. Biomaterials 2009, 30:5392-5402.

19. Wilson K, Molnar P, Hickman JJ: Integration of functional myotubes with a Bio-MEMS device for non-invasive interrogation. Lab Chip 2007, 7:920-922.

20. Wilson K, Das M, Wahl KJ, Colton RJ, Hickman J: Measurement of contractile stress generated by cultured rat muscle on silicon cantilevers for toxin detection and muscle performance enhancement. PLOS ONE 2010, 5.

21. Rumsey JW, Das M, Bhalkikar A, Stancescu M, Hickman JJ: Tissue engineering the mechanosensory circuit of the stretch reflex arc: sensory neuron innervation of intrafusal muscle fibers. Biomaterials 2010, 31:8218-8227.

22. Guo X, Spradling S, Stancescu M, Lambert S, Hickman JJ: Derivation of sensory neurons and neural crest stem cells from human neural progenitor hNP1. Biomaterials 2013, 34:4418-4427.

23. Guo X, Ayala JE, Gonzalez M, Stancescu M, Lambert S, Hickman JJ: Tissue engineering the monosynaptic circuit of the stretch reflex arc with coculture of embryonic motoneurons and proprioceptive sensory neurons. Biomaterials 2012, 33:5723-5731.

24. Long C, Finch C, Esch M, Anderson W, Shuler M, Hickman J: Design optimization of liquid-phase flow patterns for microfabricated lung on a chip. Annals Biomed Eng 2012, 40:1255-1267.

25. Mahler GJ, Esch MB, Glahn RP, Shuler ML: Characterization of a gastrointestinal tract microscale cell culture analog used to predict drug toxicity. Biotechnol Bioeng 2009, 104:193-205.

26. Mahler GJ, Shuler ML, Glahn RP: Characterization of Caco-2 and HT29-MTX cocultures in an in vitro digestion/cell culture model used to predict iron bioavailability. J Nutr Biochem 2009, 20:494-502.

27. Mahler GJ, Esch MB, Tako E, Southard TL, Archer SD, Glahn RP, Shuler ML: Oral exposure to polystyrene nanoparticles affects iron absorption. Nat Nanotechnol 2012, 7:264-271.
28. Esch MB, Sung JH, Yang J, Yu C, Yu J, March JC, Shuler ML: On chip porous polymer membranes for integration of gastrointestinal tract epithelium with microfluidic 'body-on-a-chip' devices. Biomed Microdevices 2012, 14:895-906

29. Sung JH, Yu J, Luo D, Shuler ML, March JC: Microscale 3-D hydrogel scaffold for biomimetic gastrointestinal (GI) tract model. Lab Chip 2011, 11:389-392

30. Sung JH, Shuler ML: A micro cell culture analog (microCCA) with 3-D hydrogel culture of multiple cell lines to assess metabolism-dependent cytotoxicity of anti-cancer drugs. Lab Chip 2009, 9:1385-1394.

31. Kostadinova R, Boess F, Applegate D, Suter L, Weiser T, Singer T, Naughton B, Roth A: A long-term three dimensional liver co-culture system for improved prediction of clinically relevant drug-induced hepatotoxicity. Toxicol Appl Pharmacol 2013, 268:1-16.

32. Harris S, Shuler M: Growth of endothelial cells on microfabricated silicon nitride membranes for an in vitro model of the blood-brain barrier. Biotechnol Bioprocess Eng 2003, 8:246-251.

33. Lippmann ES, Azarin SM, Kay JE, Nessler RA, Wilson HK, Al-Ahmad A, Palecek SP, Shusta EV: Derivation of blood-brain barrier endothelial cells from human pluripotent stem cells. Nat Biotechnol 2012, 30:783-791.

34. Shayan G, Choi YS, Shusta EV, Shuler ML, Lee KH: Murine in vitro model of the blood-brain barrier for evaluating drug transport. Eur J Pharm Sci 2011 42:148-155.

35. Esch MB, Post DJ, Shuler ML, Stokol T: Characterization of in vitro endothelial linings grown within microfluidic channels. Tissue Eng Part A 2011, 17:2965-2971.

36. Viravaidya K, Shuler ML: Incorporation of 3T3-L1 cells to mimic bioaccumulation in a microscale cell culture analog device for toxicity studies. Biotechnol Progress 2004, 20:590-597.

doi: $10.1186 /$ scrt370

Cite this article as: Smith AST, et al:: Microphysiological systems and lowcost microfluidic platform with analytics. Stem Cell Research \& Therapy 2013, 4(Suppl 1):S9. 